\title{
Caracterização química de sementes e tortas de pinhão-manso, nabo-forrageiro e crambe
}

\author{
Anderson Dias Vieira de Souza(1), Simone Palma Fávaro(1), Luis Carlos Vinhas Ítavo(1) \\ e Renato Roscoe(2)
}

(1)Universidade Católica Dom Bosco, Avenida Tamandaré, no 6.000, Jardim Seminário, Caixa Postal 100, CEP 79117-900 Campo Grande, MS. E-mail: anderson.dias.vieira@hotmail.com, itavo@ucdb.br, simone.palma@ucdb.br (2)Fundação MS para Pesquisa e Difusão de Tecnologias Agropecuárias, Entrada da Usina Velha, Km 02, Caixa Postal 105, CEP 79150-000 Maracaju, MS. E-mail: renatoroscoe@hotmail.com

Resumo - O objetivo deste trabalho foi realizar caracterização química de sementes e de tortas de pinhão-manso (Jatropha curcas), nabo-forrageiro (Raphanus sativus) e crambe (Crambe abyssinica) após a extração do óleo por prensagem mecânica. Sementes inteiras dessas espécies foram submetidas à dupla prensagem a frio para extração do óleo, produto principal, e da torta, coproduto. Os grãos e tortas foram avaliados quanto à composição bromatológica e ao perfil de minerais. Os rendimentos de extração lipídica foram calculados com base no balanço de massas. O teor de lipídeos nas tortas foi baixo quando comparado aos valores da literatura, o que caracteriza boa eficiência de extração e versatilidade da prensa empregada. A torta de pinhão-manso apresenta fibras como principal componente, com cerca de $1 / 3$ de sua composição total. As proteínas constituem a fração majoritária na torta de nabo-forrageiro, e o crambe apresenta composição balanceada entre fibras e proteínas. As tortas são ricas em potássio, magnésio, cálcio, sódio, manganês, ferro, zinco e boro.

Termos para indexação: Crambe abyssinica, Jatropha curcas, Raphanus sativus, biodiesel, composição bromatológica, resíduos agroindustriais.

\section{Chemical characterization of seeds and presscakes of physic nut, radish and crambe}

\begin{abstract}
The objective of this work was to chemically characterize the seeds and presscakes of physic nut (Jatropha curcas), radish (Raphanus sativus) and crambe (Crambe abyssinica) after extracting the oil with a mechanical press. Whole seeds of these species were subjected to double cold pressing to extract the oil, or main product, and the presscake, or coproduct. The seeds and presscakes were evaluated regarding proximate composition and mineral profile. The lipid contents in the presscakes were lower when compared to the values presented in previous works, which characterizes good extraction efficiency and versatility of the employed press. Fibers are the most abundant component of physic nut presscakes, and comprise about $1 / 3$ of their total composition. Protein is the largest fraction in radish presscakes, and crambe presents balanced fiber and protein contents. The presscakes are rich in potassium, magnesium, calcium, sodium, manganese, iron, zinc and boron.
\end{abstract}

Index terms: Crambe abyssinica, Jatropha curcas, Raphanus sativus, biodiesel, proximate composition, agroindustrial waste.

\section{Introdução}

Estudos sobre o aproveitamento de coprodutos gerados na cadeia produtiva do biodiesel são bastante incipientes (Neiva Júnior et al., 2007) e merecem investigações de maior profundidade, já que muitas cadeias somente serão viáveis economicamente quando esses resíduos agregarem valor aos sistemas de produção.

No Brasil, grande quantidade de coprodutos da agricultura e da agroindústria tem potencial para uso na alimentação de animais, como os oriundos da cadeia do biodiesel (tortas e farelos) (Van Cleef, 2008), que podem ser empregados como fontes de nutrientes para animais por serem prontamente degradados no rúmen (Krishna, 1985). No entanto, alguns fatores, como o armazenamento, restringem a utilização desses coprodutos e, em alguns casos, existe a necessidade de tratamentos para a melhoria de seu valor nutritivo (Smith et al., 1988). Deve-se considerar também o seu aproveitamento na nutrição humana, de forma direta ou como fonte para o isolamento de moléculas, como 
a produção de concentrados protéicos. Outra possível aplicação é o uso como adubos orgânicos, que podem representar significativos aportes de nutrientes ao solo e às plantas cultivadas (Tigere et al., 2006).

As tortas são obtidas após a extração mecânica do óleo das sementes e os farelos após a extração por solventes. $\mathrm{Na}$ extração por prensagem, o teor de óleo observado nas tortas depende da espécie processada e das especificações das prensas, e varia entre 15 e $27 \%$ para grãos como algodão, girassol, pinhão-manso e nabo-forrageiro (Neiva Júnior, 2007; Van Cleef, 2008).

Os farelos geram um resíduo bastante inferior de óleos, da ordem de 1,5\%, o que resulta em maior teor de proteína bruta (Anderson et al., 2000; Rakshit et al., 2008). Deve-se salientar que, apesar de ser menos eficiente na retirada da fração lipídica, a extração por prensa constitui o sistema mais viável em pequena escala, por não depender das exigências de instalações e segurança inerentes ao processamento com uso de solvente.

No Brasil, a principal matéria prima para a produção de óleo é a soja, responsável por mais de $70 \%$ do biodiesel produzido no país (Brasil, 2009). Nesse sentido, há uma busca por novas oleaginosas que produzam óleos não comestíveis, para a produção de biodiesel dentro das normas internacionais de qualidade. Culturas pouco conhecidas no Brasil, como o crambe (Crambe abyssinica) e o pinhão-manso (Jatropha curcas), ou conhecidas mas não trabalhadas para a produção de óleo, como o nabo-forrageiro (Raphanus sativus), despontam como alternativas interessantes para a produção de biodiesel (Wang et al., 2000; Roscoe et al., 2007).

O crambe e o nabo-forrageiro são plantas de ciclo anual da família Brassicaceae e apresentam como principais características a elevada concentração de óleo e proteína, além do grande potencial de cultivo na região Centro-Oeste. O pinhão-manso, da família Euphorbiaceae, é um arbusto de ciclo perene com elevada produção anual de óleo e com bom potencial para a agricultura familiar. Essas espécies representam matérias-primas alternativas para compor a matriz de produção de óleo para biodiesel, sobretudo na região Centro-Oeste do Brasil.

Por serem espécies ainda pouco conhecidas e sem uma cadeia produtiva estabelecida no Brasil, são escassas as informações sobre suas tortas e farelos. A caracterização desses co-produtos é de extrema importância na avaliação da viabilidade dessas novas oleaginosas, uma vez que a composição dessas tortas e farelos pode ser decisiva na definição de seus usos potenciais.

O objetivo deste trabalho foi avaliar a composição química de sementes e tortas de pinhão-manso, nabo-forrageiro e crambe, obtidas após a extração do óleo por prensagem mecânica.

\section{Material e Métodos}

Foram utilizadas amostras de grãos de nabo-forrageiro (Raphanus sativus), cultivar IPR 116, provenientes do Instituto Agronômico do Paraná, e de crambe (Crambe abyssinica), cultivar FMS Brilhante, da Fundação MS. Os grãos de pinhão-manso (Jatropha curcas) foram obtidos a partir de acesso selecionado pela Fazenda Paraíso, em Itaum, no Município de Dourados, MS.

As tortas foram obtidas por meio de dupla prensagem dos grãos inteiros, em prensa mecânica tipo "expeller", de aço inoxidável, com capacidade para extração de $150 \mathrm{~kg} \mathrm{~h}^{-1}$, com a qual obteve-se temperaturas médias de saída da torta entre 90 e $110^{\circ} \mathrm{C}$. As sementes e tortas obtidas foram homogeneizadas em moinho analítico de laboratório (modelo IKA A11 basic, Quimis, Diadema, SP) e armazenadas a $-18^{\circ} \mathrm{C}$, até a realização das análises.

O teor de nitrogênio foi quantificado pelo método micro-Kjeldahl e transformado em proteína pelo uso do fator de correção 6,25. Os lipídeos foram extraídos em aparelho Soxhlet, com uso de hexano como solvente. O teor de cinzas, ou resíduo mineral fixo, foi determinado por incineração em mufla, a $550^{\circ} \mathrm{C}$. O teor de matéria seca foi determinado em estufa a $105^{\circ} \mathrm{C}$, até massa constante (Williams, 1984).

A fração glicídica foi extraída de acordo com o método de Lane-Eynon (Brasil, 2005) e quantificada colorimetricamente pelo método de Somogyi-Nelson (Nelson, 1944) em espectrofotometria a $510 \mathrm{~nm}$, utilizando uma curva padrão construída a partir de uma solução de glicose $\left(100 \mathrm{mg} \mathrm{mL}^{-1}\right)$, com intervalo de 40 a $200 \mu \mathrm{g}$.

A fibra alimentar foi determinada pelo cálculo da diferença entre $100 \mathrm{~g}$ da amostra e a soma total dos valores encontrados para teor de umidade, lipídeos, proteína bruta, cinzas, glicose, sacarose e amido, para 
cada amostra analisada. Todos os parâmetros avaliados foram expressos com base na matéria seca.

O rendimento da extração de óleo foi calculado em base seca (bs), por balanço de massa, antes e após a prensagem:

$\mathrm{RE}=\frac{\left(\operatorname{Lg}-\left(\frac{(100-\mathrm{Lt}) * \mathrm{Lt}}{100-\mathrm{Lt}}\right)\right) * 100}{\mathrm{Lg}}$,

em que: $\mathrm{RE}=$ rendimento em óleo $(\%) ; \mathrm{Lg}=$ teor de lipídeos no grão (bs); e $\mathrm{Lt}=$ teor de lipídeos na torta (bs).

Os incrementos de fibra alimentar (IF) e proteína bruta (IPB) nas tortas foram calculados a partir dos teores de fibra e proteína em base seca, conforme as equações:

$\mathrm{IF}=\frac{(\mathrm{Ft}-\mathrm{Fg})}{\mathrm{Fg}} * 100$, em que: $\mathrm{Fg}$ é o teor de fibra no grão (bs); e Ft = teor de fibra na torta (bs).

$\mathrm{IPB}=\frac{(\mathrm{Pt}-\mathrm{Pg})}{\mathrm{Pg}} * 100$, em que: Pg é o teor de proteína bruta no grão (bs); e Pt é o teor de proteína bruta na torta (bs).

Após a incineração das amostras e ressuspensão das cinzas em $\mathrm{HCl} 2 \mathrm{~N}$, foi feita a quantificação de minerais nos grãos e tortas em espectrofotômetro de absorção atômica (SpectrAA 240FS, Varian Inc., Palo Alto, CA, EUA), para determinação de alumínio (Al), bário $(\mathrm{Ba})$, boro $(\mathrm{B})$, cádmio $(\mathrm{Cd})$, cálcio $(\mathrm{Ca})$, chumbo $(\mathrm{Pb})$, cobalto $(\mathrm{Co})$, cobre $(\mathrm{Cu})$, cromo $(\mathrm{Cr})$, ferro $(\mathrm{Fe})$, magnésio ( $\mathrm{Mg}$ ), manganês ( $\mathrm{Mn})$, molibdênio (Mo), níquel $(\mathrm{Ni})$, potássio $(\mathrm{K})$, prata $(\mathrm{Ag})$, sódio $(\mathrm{Na})$ e zinco ( $\mathrm{Zn}$ ), e em gerador de vapor (VGA 77, Varian Inc., Palo Alto, CA, EUA), para determinação de mercúrio $(\mathrm{Hg})$, estanho $(\mathrm{Sn})$, antimônio $(\mathrm{Sb})$, selênio (Se) e arsênio (As). Os minerais quantificados foram expressos em mg $100 \mathrm{~g}^{-1}$.

O delineamento experimental foi em blocos ao acaso, com quatro repetições e análises em triplicata. As sementes e as tortas resultantes da prensagem a frio foram avaliadas em cada espécie. Para comparação entre semente e torta da mesma espécie, as médias foram submetidas ao teste t de Student, a 5\% de probabilidade. Foram utilizados a análise de variância e o teste de Tukey a $5 \%$ de probabilidade para comparação entre espécies, com uso dos procedimentos TTEST e GLM do pacote estatístico SAS System, versão 9.1.3 (SAS Institute, 2004).

\section{Resultados e Discussão}

O teor de água dos grãos, inferido a partir dos valores de matéria seca (Tabela 1), variou dentro da faixa ótima para armazenamento de oleaginosas, que está ente 6 e 10\% (Brooker et al. 1992). Observou-se menor umidade dos grãos e das tortas de pinhão-manso em relação às demais espécies. Nas tortas, esse resultado provavelmente está relacionado à variação na absorção de água pelas diferentes espécies, durante o resfriamento após a prensagem. A temperatura final da torta na saída da prensa variou entre 90 e $110^{\circ} \mathrm{C}$, e o resfriamento ocorreu em ambiente aberto, o que possibilitaria a reabsorção de água. Esses valores, no entanto, estão dentro do limite de $11 \%$ de umidade, ou seja, $89 \%$ de matéria seca, recomendado para o armazenamento de farelos de oleaginosas (Athié et al., 1998; Custódio et al., 2005).

O crambe apresentou o maior teor de lipídeos nos grãos (Tabela 1) sem diferir estatisticamente, no entanto, dos apresentados pelo pinhão-manso, mas com resultados acima das médias relatadas na literatura. Carlson \& Tookey (1983) sistematizaram os dados de vários autores, num total de 75 amostras de 17 regiões dos Estados Unidos, e observaram média de 35,3\% de lipídeos em sementes de crambe com casca e de $46,5 \%$ em sementes descascadas. Valores semelhantes foram obtidos por Wang et al. (2000) em cultivos na

Tabela 1. Composição química (\% da matéria seca) de sementes e tortas de pinhão-manso, nabo-forrageiro e crambe $^{(1)}$.

\begin{tabular}{lccr}
\hline Composição & Pinhão-manso & Nabo-forrageiro & Crambe \\
\hline & & Sementes \\
Matéria seca & $93,76 \pm 0,06 \mathrm{bB}$ & $92,10 \pm 0,19 \mathrm{bA}$ & $91,61 \pm 0,29 \mathrm{aA}$ \\
Lipídeos & $40,33 \pm 1,91 \mathrm{aAB}$ & $36,85 \pm 0,31 \mathrm{aB}$ & $44,10 \pm 1,46 \mathrm{aA}$ \\
Proteína bruta & $20,95 \pm 0,58 \mathrm{bB}$ & $28,19 \pm 0,53 \mathrm{bA}$ & $21,30 \pm 1,86 \mathrm{bB}$ \\
Cinzas & $4,95 \pm 0,005 \mathrm{aA}$ & $4,10 \pm 0,07 \mathrm{bB}$ & $5,08 \pm 0,21 \mathrm{bA}$ \\
Glicose & $0,18 \pm 0,01 \mathrm{bB}$ & $1,17 \pm 0,06 \mathrm{aA}$ & $1,32 \pm 0,24 \mathrm{aA}$ \\
Sacarose & $1,35 \pm 0,34 \mathrm{aB}$ & $5,89 \pm 0,27 \mathrm{aA}$ & $1,83 \pm 0,04 \mathrm{aB}$ \\
Amido & $9,85 \pm 1,55 \mathrm{bB}$ & $14,05 \pm 0,74 \mathrm{aA}$ & $14,75 \pm 2,35 \mathrm{aA}$ \\
Fibra alimentar & $20,45 \pm 3,66 \mathrm{bA}$ & $9,98 \pm 0,66 \mathrm{bB}$ & $13,32 \pm 0,56 \mathrm{bB}$ \\
\hline & & Tortas & \\
Matéria seca & $91,73 \pm 0,11 \mathrm{aC}$ & $91,37 \pm 0,05 \mathrm{aB}$ & $91,18 \pm 0,06 \mathrm{aA}$ \\
Lipídeos & $14,21 \pm 1,01 \mathrm{bAB}$ & $11,73 \pm 1,27 \mathrm{bB}$ & $15,88 \pm 0,25 \mathrm{bA}$ \\
Proteína bruta & $28,66 \pm 0,45 \mathrm{aC}$ & $49,47 \pm 0,53 \mathrm{aA}$ & $31,73 \pm 0,17 \mathrm{aB}$ \\
Cinzas & $5,94 \pm 0,31 \mathrm{aAB}$ & $5,25 \pm 0,21 \mathrm{aB}$ & $6,30 \pm 0,01 \mathrm{aA}$ \\
Glicose & $0,25 \pm 0,04 \mathrm{aC}$ & $1,15 \pm 0,09 \mathrm{aB}$ & $1,48 \pm 0,19 \mathrm{aA}$ \\
Sacarose & $1,83 \pm 0,33 \mathrm{aB}$ & $4,57 \pm 0,18 \mathrm{bA}$ & $1,55 \pm 0,26 \mathrm{bB}$ \\
Amido & $12,00 \pm 0,72 \mathrm{aB}$ & $14,79 \pm 1,63 \mathrm{aA}$ & $15,00 \pm 1,26 \mathrm{aA}$ \\
Fibra alimentar & $36,68 \pm 1,20 \mathrm{aA}$ & $13,70 \pm 1,96 \mathrm{aC}$ & $27,96 \pm 1,35 \mathrm{aB}$ \\
\hline
\end{tabular}

${ }^{(1)}$ Média \pm desvio-padrão seguidas por letras iguais, minúsculas nas comparações entre composição de sementes e tortas e maiúsculas nas linhas, não diferem pelos testes t e de Tukey, a 5\% de probabilidade, respectivamente. 
China. Esses valores indicam que a variedade FMS Brilhante, nas condições dos estados de Mato Grosso e Mato Grosso do Sul, de onde as amostras de grão foram provenientes, apresenta teores mais elevados de óleo que as variedades cultivadas nos Estados Unidos na década de 1980.

A média da concentração de lipídeos nas sementes integrais de pinhão-manso observada neste trabalho (Tabela 1) também foi maior que as médias comumente relatadas na literatura. Materiais provenientes de diferentes acessos de Pinhão Manso da região de Januária, MG, foram analisados pela Cetec (Fundação Centro Tecnológico de Minas Gerais, 1983) e apresentaram teores médios de lipídeos de 38,1\%, em base seca. Em revisão realizada com grãos de pinhão-manso provenientes de São Tomé e Príncipe e de Cabo Verde, Heller (1996) relatou teores totais de óleo nos grãos com variação entre 23,7 e $34,1 \%$, com média de $30,2 \%$. Entretanto, esses valores eram referentes ao peso úmido das sementes. Penha et al. (2007), também para grãos integrais sem correção para umidade, obtiveram teores de 31,6\% de lipídeos, em grãos de pinhão-manso cultivado no Estado do Maranhão.

O nabo-forrageiro, apesar de não ter casca externa, apresentou os menores teores de lipídeos (36,85\%) entre as espécies estudadas, sem, contudo, diferir estatisticamente do pinhão-manso (Tabela 1). Valores semelhantes foram obtidos por Mandal et al. (2002) ao analisar um grande banco de germoplasma de brássicas da Índia, em que os teores de lipídeos em nabo-forrageiro estiveram entre 30,7 e $35,6 \%$, com média de 33,0\%.

Os teores de proteína bruta nos grãos das oleaginosas estudadas variaram entre 20,95 e 28,19\% (Tabela 1). Após a extração de óleo, os teores de proteína nas respectivas tortas aumentaram para patamares entre 28,66 e $49,47 \%$, com maiores teores para o nabo-forrageiro, tanto em sementes quanto em tortas. Esses valores são relativamente elevados e classificam essas tortas como potenciais alimentos proteicos em dietas animais (Abdalla et al., 2008). Na literatura, observou-se teores de proteína bruta entre 32 e $38 \%$, inferiores aos valores relatados no presente estudo (Neiva Júnior et al., 2007; Abdalla et al., 2008; Mello et al., 2008; Van Cleef, 2008). O volume de dados sobre farelo de nabo-forrageiro disponível na literatura é ainda limitado, o que não permite discussões aprofundadas quanto à divergência observada em relação aos resultados do presente estudo. O teor de proteínas em oleaginosas pode variar com os genótipos e as condições ambientais (Mosse \& Baudet, 1983), além de ser dependente da eficiência de extração de óleo, o que permitiria variações como as observadas.

O teor médio de proteínas observado nos grãos de pinhão-manso (Tabela 1) está de acordo com os teores documentados na literatura. Penha et al. (2007) obtiveram valores de proteína bruta da ordem de $14,5 \%$ em sementes inteiras de pinhão-manso, e de $26,1 \%$ no albúmen. Makkar et al. (1998), ao trabalhar com sementes tóxicas e não tóxicas do México, obtiveram valores de proteína bruta no albúmen que variaram entre 22 a $28 \%$. Analogamente, Heller (1996) encontrou valores de proteína bruta no albúmen que variaram entre 20,3 e 28,4\%, com média de $24,1 \%$. A torta de pinhão-manso apresentou $28,7 \%$ de proteína bruta em base seca. Essa concentração foi superior às das tortas estudadas por Neiva Júnior et al. (2007) e por Van Cleef (2008), que obtiveram, respectivamente, 25,4 e $18,8 \%$ de proteína.

A quantidade de fibra alimentar no grão e na torta foi maior no pinhão-manso, seguido pelo crambe e pelo nabo-forrageiro (Tabela 1). Os grãos de pinhão-manso e de crambe são envoltos por uma casca externa rica em fibras (Carlson \& Tookey, 1983; Heller, 1996). O nabo-forrageiro, por sua vez, não apresenta tal estrutura, o que justifica a menor quantidade de fibras em seus grãos e na torta resultante. Carlson \& Tookey (1983) relataram que os teores de fibra bruta em crambe foram de 14,3, 3,6 e $22,1 \%$ para grãos inteiros, descascados e para a casca, respectivamente, o que demonstra o acúmulo de fibras na parte mais externa do grão.

O teor de cinzas nos grãos de pinhão-manso e crambe foi mais elevado do que o de nabo-forrageiro (Tabela 1). Penha et al. (2007) observaram médias de 3,7\% para cinzas em grãos integrais de pinhão-manso e de 3,61\% para cinzas no albúmen dessa oleaginosa. Na torta de pinhão-manso, detectaram-se valores similares aos observados em outros estudos, enquanto a torta de nabo-forrageiro apresentou teores inferiores (Neiva Júnior et al., 2007; Van Cleef, 2008).

$\mathrm{Na}$ fração glicídica, o amido foi o componente mais abundante, com os maiores teores nos grãos e tortas de nabo-forrageiro e crambe (Tabela 1). Não 
houve diferença significativa no conteúdo de amido após a extração do óleo, exceto no pinhão-manso. A concentração de sacarose mostrou-se superior no grão e na torta de nabo-forrageiro. A semente e a torta de pinhão-manso apresentaram cerca de seis vezes menos glicose do que as amostras de nabo e crambe.

O rendimento de extração de óleo bruto, independentemente do tipo de oleaginosa prensada, foi de 77\%, em média (Tabela 2). Pighinelli et al. (2009) verificaram que o rendimento de extração de óleo de girassol pelo mesmo sistema de prensagem, mas com uso de equipamento de outro fabricante, variou de 49 a $65 \%$, e que o aumento da umidade dos grãos influenciou negativamente na eficiência de extração de óleo. Em estudo com pinhão-manso utilizando prensas semelhantes à do presente trabalho, Beerens (2007) obteve valores de extração de óleo entre 79 e $87 \%$ do total, com umidade inicial da semente em torno de $6,5 \%$. A baixa umidade nas sementes utilizadas neste trabalho e a dupla prensagem contribuíram para a boa eficiência na extração da fração lipídica. Beerens (2007) argumenta que teores de umidade inicial mais elevados nos grãos reduzem a eficiência de extração de óleo, pois elevam a capacidade de deformação do material (o que reduz a ruptura), além de aumentarem a emulsificação e plasticidade da massa, que reduzem a sua viscosidade e facilitam a passagem pela prensa.

Os incrementos nos teores de proteína bruta e fibra alimentar do grão para a torta mostraram comportamento oposto entre as diferentes oleaginosas (Tabela 2). O pinhão-manso e o crambe, com casca rica em fibras, tiveram os maiores incrementos em fibras alimentares após a extração do óleo. Para o nabo-forrageiro, no entanto, o incremento no teor de proteína bruta foi maior.

Dentre os minerais avaliados, os mais abundantes nos grãos e tortas foram o potássio, magnésio, sódio e cálcio, seguidos por ferro, boro e zinco (Tabela 3).

Tabela 2. Rendimento de extração de óleo em sementes, incremento de proteína bruta e fibra alimentar nas tortas obtidas por prensagem a frio em pinhão-manso, nabo-forrageiro e crambe ${ }^{(1)}$.

\begin{tabular}{lcc}
\hline Variáveis & Pinhão-manso & Nabo-forrageiro \\
\hline Rendimento de extração de óleo (\%) & $74,46 \pm 1,62 \mathrm{a}$ & $77,18 \pm 2,63 \mathrm{a}$ \\
Incremento de proteína bruta (\%) & $36,85 \pm 1,83 \mathrm{c}$ & $75,53 \pm 3,53 \mathrm{a}$ \\
Incremento de fibra alimentar (\%) & $98,03 \pm 5,89 \mathrm{a}$ & $48,43 \pm 1,39 \mathrm{~b}$ \\
\hline (1)Média $\%$ desvio-padrão seguidas de letras iguais não diferem pelo teste de Tukey, a 5\% de probabilidade. Valores expressos com base na matéria seca.
\end{tabular}

${ }^{(1)}$ Média \pm desvio-padrão seguidas de letras iguais não diferem pelo teste de Tukey, a 5\% de probabilidade. Valores expressos com base na matéria seca.

Tabela 3. Composição mineral (mg $\left.100 \mathrm{~g}^{-1}\right)$ observada nas sementes e tortas de pinhão-manso, nabo-forrageiro e crambe(1).

\begin{tabular}{|c|c|c|c|c|c|c|}
\hline \multirow[t]{2}{*}{ Mineral } & \multicolumn{2}{|c|}{ Pinhão-manso } & \multicolumn{2}{|c|}{ Nabo-forrageiro } & \multicolumn{2}{|c|}{ Crambe } \\
\hline & Semente & Torta & Semente & Torta & Semente & Torta \\
\hline $\mathrm{K}$ & 487,58 & 526,52 & 402,96 & $1.210,21$ & 935,12 & 565,54 \\
\hline $\mathrm{Mg}$ & 446,54 & 502,00 & 404,60 & 471,23 & 281,00 & 345,64 \\
\hline $\mathrm{Ca}$ & 444,07 & 495,78 & 355,56 & 452,49 & 460,65 & 854,69 \\
\hline $\mathrm{Na}$ & 77,24 & 30,80 & 40,87 & 21,42 & 18,43 & 48,60 \\
\hline $\mathrm{Fe}$ & 4,30 & 3,52 & 7,22 & 9,26 & 8,64 & 8,41 \\
\hline B & 4,41 & 5,37 & 1,42 & 2,41 & 0,71 & 2,73 \\
\hline $\mathrm{Zn}$ & 1,69 & 2,18 & 3,15 & 7,12 & 3,90 & 4,27 \\
\hline $\mathrm{Mn}$ & 1,01 & 1,23 & 0,63 & 2,96 & 2,77 & 0,93 \\
\hline $\mathrm{Cu}$ & 0,68 & 0,86 & 0,10 & 1,29 & 1,44 & 0,54 \\
\hline $\mathrm{Ba}$ & 0,91 & 0,34 & 0,63 & 1,35 & 1,28 & 0,78 \\
\hline $\mathrm{Al}$ & 0,49 & 0,40 & 2,31 & 0,05 & $<0,05$ & 3,19 \\
\hline $\mathrm{Ni}$ & 0,24 & 0,03 & 0,46 & 0,16 & 0,12 & 0,03 \\
\hline $\mathrm{Hg}$ & 0,0004 & 0,0010 & 0,0001 & 0,0005 & 0,0006 & 0,00066 \\
\hline As & $<0,002$ & $<0,002$ & $<0,002$ & 0,05 & 0,03 & 0,003 \\
\hline Mo & $<0,02$ & $<0,02$ & $<0,02$ & 0,11 & 0,08 & 0,03 \\
\hline $\mathrm{Pb}$ & $<0,02$ & $<0,02$ & $<0,02$ & 0,06 & 0,05 & 0,03 \\
\hline $\mathrm{Co}$ & $<0,02$ & $<0,02$ & $<0,02$ & 0,14 & 0,16 & 0,03 \\
\hline $\mathrm{Cd}$ & $<0,02$ & $<0,02$ & $<0,02$ & $<0,02$ & $<0,02$ & 0,03 \\
\hline $\mathrm{Cr}$ & $<0,02$ & $<0,02$ & $<0,02$ & $<0,02$ & $<0,02$ & 0,03 \\
\hline $\mathrm{Ag}$ & $<0,02$ & $<0,02$ & $<0,02$ & $<0,02$ & $<0,02$ & 0,03 \\
\hline $\mathrm{Sb}$ & $<0,002$ & $<0,002$ & $<0,002$ & $<0,002$ & $<0,002$ & 0,003 \\
\hline $\mathrm{Sn}$ & $<0,002$ & $<0,002$ & $<0,002$ & $<0,002$ & $<0,002$ & 0,003 \\
\hline $\mathrm{Se}$ & $<0,002$ & $<0,002$ & $<0,002$ & $<0,002$ & $<0,002$ & 0,003 \\
\hline
\end{tabular}

(1) Valores expressos com base na matéria seca. 
$\mathrm{Na}$ torta de crambe, destacou-se o elevado teor de cálcio. Vargas-Lopez et al. (1999) quantificaram alguns minerais na semente inteira de crambe e encontraram teor

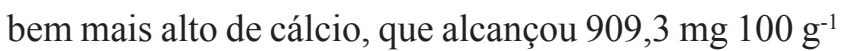
de semente. Os valores quantificados por esses autores para potássio foram de 299,9 e $1.147,9 \mathrm{mg} 100 \mathrm{~g}^{-1} \mathrm{de}$ semente, próximos aos observados em grãos de crambe neste trabalho. Segundo Chivandi et al. (2004), farelos e tortas de pinhão-manso obtidos por diferentes métodos de extração de óleo apresentaram $811 \mathrm{mg} 100 \mathrm{~g}^{-1} \mathrm{de}$ cálcio em tortas resultantes de extração por prensagem a frio somente do albúmen do grão. Quando a extração foi por meio de solvente, o teor de cálcio aumentou

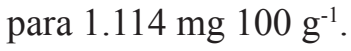

A torta de nabo-forrageiro mostrou-se bastante rica em potássio (Tabela 3) em comparação aos farelos de arroz e cevada, que apresentam em torno de 540 e $30 \mathrm{mg} 100 \mathrm{~g}^{-1}$, respectivamente, segundo Silva Filho et al. (1999). Esses autores, no entanto, observaram quase o dobro da concentração de potássio no farelo de soja. O potássio é um dos elementos mais exigidos por ruminantes para o ganho de peso, e sua alta concentração na ração reduz o custo de suplementação.

O conteúdo observado de sódio foi elevado em comparação com outros trabalhos. Silva Filho et al. (1999) detectaram $13 \mathrm{mg} 100 \mathrm{~g}^{-1} \mathrm{em}$ farelo de canola e $0,6 \mathrm{mg} 100 \mathrm{~g}^{-1} \mathrm{em}$ farelo de soja. O teor desse elemento em sementes de crambe inteiras, investigado por Vargas-Lopez et al. (1999), foi de 9,3 mg $100 \mathrm{~g}^{-1}$.

As concentrações de ferro nas tortas revelaramse inferiores às de outros coprodutos citados na literatura, como em farelo de algodão (15 mg $\left.100 \mathrm{~g}^{-1}\right)$, farelo de canola (32,9 mg $100 \mathrm{~g}^{-1}$ ) e farelo de soja (21 mg $100 \mathrm{~g}^{-1}$ ) (Silva Filho et al., 1999). No entanto, no presente estudo, os grãos de crambe e nabo forrageiro apresentaram valores mais altos do que a concentração de 5,5 mg $100 \mathrm{~g}^{-1}$ observada por Vargas-Lopez et al. (1999). A torta de nabo-forrageiro apresentou os maiores conteúdos de zinco, cujo teor em leguminosas como soja e amendoim pode apresentar valores médios de $7 \mathrm{mg} 100 \mathrm{~g}^{-1}$ (National Research Council, 1980).

As quantidades verificadas de alumínio, bário, boro, cobre, manganês e níquel foram baixas. Os elementos antimônio, arsênio, cádmio, chumbo, cobalto, cromo, estanho, molibdênio, prata e selênio não foram quantificados por estar abaixo do limite de detecção do aparelho.
Baixos teores de mercúrio foram detectados nas amostras, a exemplo do observado por Silva Filho et al. (1999), que também verificaram pequenas quantidades de mercúrio em diversos tipos de farelos. O monitoramento dos metais pesados, como mercúrio, chumbo, arsênico e cádmio, é importante em razão da toxicidade desses metais quando em níveis superiores aos estabelecidos como seguros para dietas animais (National Research Council, 1980).

Os resultados apresentados neste trabalho trazem subsídios para a utilização das tortas como fontes de nutrientes em rações animais. Em geral, todas as tortas podem ser consideradas como alimentos proteicos potenciais (Abdalla et al., 2008), com destaque para a torta de nabo-forrageiro. As tortas de pinhão-manso e crambe, obtidas a partir do esmagamento dos grãos com casca, apresentaram maiores teores de fibras alimentares em detrimento dos teores de proteína bruta (Tabela 1). O descascamento dessas oleaginosas antes da prensagem pode melhorar seus conteúdos de proteína bruta. Entretanto, também pode reduzir a abrasão da massa e, com isso, dificultar o seu processamento em prensas tipo "expeller" (Beerens, 2007). Estudos complementares devem abordar esses aspectos.

Ressalta-se que, para a incorporação desses coprodutos como fonte alimentar, faz-se necessária a complementação dos estudos no tocante à toxicidade e a fatores antinutricionais presentes nas tortas das espécies avaliadas (Martinez-Herrera et al., 2006). Embora elas apresentem bom potencial para utilização na alimentação animal, sua toxicidade e seus fatores antinutricionais podem inviabilizá-las como alternativas caso os processos de tratamento para desintoxicação sejam economicamente inviáveis.

\section{Conclusões}

1. Em todos os parâmetros avaliados, as tortas de pinhão-manso, nabo-forrageiro e crambe apresentam potencial para utilização na alimentação animal ou humana, com altos teores de proteína bruta, carboidratos e fibras alimentares.

2. As tortas de pinhão-manso, nabo-forrageiro e crambe podem ser classificadas como alimentos proteicos, embora a torta de pinhão-manso apresente como componente principal as fibras.

3. As proteínas são a fração majoritária na torta de nabo-forrageiro, e o crambe apresenta composição balanceada entre esses elementos.

Pesq. agropec. bras., Brasília, v.44, n.10, p.1328-1335, out. 2009 
4. Os teores de minerais presentes nas tortas de pinhão-manso, nabo-forrageiro e crambe são compatíveis com sua utilização na alimentação animal e humana, e a presença de metais pesados encontra-se em teores que não oferecem riscos para esse fim.

\section{Referências}

ABDALlA, A.L.; SILVA FILHO, J.C. da; GODOI, A.R. de; CARMO, C. de A.; EDUARDO, J.L. de P. Utilização de subprodutos da indústria de biodiesel na alimentação de ruminantes. Revista Brasileira de Zootecnia, v.37, p.260-258, 2008.

ANDERSON, V.L.; CATON, J.S.; KIRSCH, J.D.; REDMER, D.A. Effect of crambe meal on performance, reproduction, and thyroid hormone levels in gestating and lactating beef cows. Journal of Animal Science, v.78, p.2269-2274, 2000.

ATHIÊ, I.; CASTRO, M.F.P.M. de; GOMES, R.A.R.; VALENTINI, S.R.T. Conservação de grãos. Campinas: Fundação Cargill, 1998. $236 \mathrm{p}$.

BEERENS, P. Screw-pressing of Jatropha seeds for fuelling purposes in less developed countries. 2007. 87p. Thesis (Master) - Eindhoven University of Technology, Eindhoven.

BRASIL. Ministério da Saúde. Agência Nacional de Vigilância Sanitária. Métodos físico-químicos para análises de alimentos. 4.ed. Brasília: Ministério da Saúde, 2005. 1018p.

BRASIL. Ministério de Minas e Energia. Boletim Mensal dos Combustíveis Renováveis, n.20, 2009. Disponível em: <http:// www.mme.gov.br>. Acesso em: 02 Maio 2009.

BROOKER, D.B.; BAKKER-ARKEMA, F.W.; HALL, C.W. Theory and simulation of grain drying. In: BROOKER, D.B.; BAKKER-ARKEMA, F.W.; HALL, C.W. Drying and storage of grains and oilseeds. New York: Van Nostrand Reinholdy, 1992. p.205-240.

CARLSON, K.D.; TOOKEY, H.L. Crambe meal as a protein source for feeds. Journal of the American Oil Chemists' Society, v.60, p.1979-1985, 1983.

CHIVANDI, E.; MTIMUNI, J.P.; READ, J.S.; MAKUZA, S.M. Effect of processing method on phorbol esters concentration, total phenolics, trypsin inhibitor activity and the proximate composition of the Zimbabwean Jatropha curcas provenance: a potential livestock feed. Pakistan Journal of Biological Science, v.7, p.1001-1005, 2004.

CUSTÓDIO, D.P.; BRANDSTETTER, E.V.; OLIVEIRA, I.P. de; OLIVEIRA, L.C.; SANTOS, K.J.G. dos; MACHADO, O.F.; ARAÚJO, A.A. de. Ração: alimento animal perecível. Revista Eletrônica Faculdade Montes Belos, v.1, p.131-147, 2005.

FUNDAÇÃO CENTRO TECNOLÓGICO DE MINAS GERAIS. Programa Energia: produção de combustíveis líquidos a partir de óleos vegetais. Belo Horizonte: CETECMG, 1983. 152p.

HELLER, J. Physical nut (Jatropha curcas L.): promoting the conservation and use of underutilized and neglected crops. Rome: International Plant Genetic Resources Institute, 1996. 66p.
KRISHNA, G. Nylon bag dry matter digestibility in agro-industrial by-products and wastes of the topics. Agricultural Wastes, v.13, p.155-158, 1985.

MAKKAR, H.P.S.; BECKER, K.; SCHMOOK, B. Edible provenances of Jatropha curcas from Quintana Roo state of Mexico and effect of roasting on antinutrient and toxic factors in seeds. Plant Foods for Human Nutrition, v.52, p.31-36, 1998.

MANDAL, S.; YADAV, S.; SINGH, R.; BEGUM, G.; SUNEJA, P.; SINGH, M. Correlation studies on oil content and fatty acid profile of some Cruciferous species. Genetic Resources and Crop Evolution, v.49, p.551-556, 2002.

MARTINEZ-HERRERA, J.; SIDDHURAJU, P.; FRANCIS, G.; DÁVILA-ORTIZ, G.; BECKER, K. Chemical composition, toxic/ antimetabolic constituents, and effects of different treatments on their levels, in four provenances of Jatropha curcas L. from Mexico. Food Chemistry, v.96, p.80-89, 2006.

MELLO, D.F.; FRANZOLIN NETO, R.; FERNANDES, L.B.; FRANCO, A.V.M.; ALVES, T.C. Avaliação do resíduo de nabo forrageiro extraído da produção de biodiesel como suplemento para bovinos de corte em pastagens. Revista Brasileira de Saúde e Produção Animal, v.9, p.45-56, 2008.

MOSSE, J.; BAUDET, J. Crude protein content and aminoacid composition of seeds: variability and correlations. Plant Foods for Human Nutrition, v.32, p.225-245, 1983.

NATIONAL RESEARCH COUNCIL. Mineral tolerance of domestic animals. Washington: National Academy of Sciences, 1980. 577p.

NEIVA JÚNIOR, A.P.; VAN CLEEF, E.H.C.B.; PARDO, R.M.P.; SILVA FILHO, J.C.; CASTRO NETO, P.; FRAGA, A.C. Subprodutos agroindustriais do biodiesel na alimentação de ruminantes. In: CONGRESSO DA REDE BRASILEIRA DE TECNOLOGIA DO BIODIESEL, 2., 2007, Brasília. Anais. Brasília: MCT/ABIPTI, 2007.

NELSON, N. A photometric adaptation of the Somogyi method for the determination of glucose. The Journal of Biological Chemistry, v.153, p.136-175, 1944.

PENHA, M. da N.C.; SILVA, M.D.P.; MENDONÇA, K.K.M.; BRANDÃO, K.S.R.; MACIEL, A.P.; SILVA, F.C. Caracterização físico-química da semente e óleo de pinhão manso (Jatropha curcas) cultivado no Maranhão. In: CONGRESSO DA REDE BRASILEIRA DE TECNOLOGIA DE BIODIESEL, 2., 2007, Brasília. Anais. Brasília: MCT/ABIPTI, 2007.

PIGHINELLI, A.L.M.T.; PARK, K.J.; RAUEN, A.M.; OLIVEIRA, R.A. de. Otimização da prensagem de grãos de girassol e sua caracterização. Revista Brasileira de Engenharia Agrícola e Ambiental, v.13, p.63-67, 2009.

RAKSHIT, K.D.; DARUKESHWARA, J.; RATHINA RAJ, K.; NARASIMHAMURTHY, K.; SAIBABA, P.; BHAGYA, S. Toxicity studies of detoxified Jatropha meal (Jatropha curcas) in rats. Food and Chemical Toxicology, v.46, p.3621-3625, 2008.

ROSCOE, R.; RICHETTI, A.; MARANHO, E. Análise de viabilidade técnica de oleaginosas para produção de biodiesel em Mato Grosso do Sul. Revista de Política Agrícola, v.16, p.48-59, 2007. 
SAS INSTITUTE. SAS OnlineDoc. Version 9.1.3. Cary: SAS Institute, 2004. 1 CD-ROM.

SILVA FILHO, J.C. da; ARMELIN, M.J.A.; SILVA, A.G. da. Determinação da composição mineral de subprodutos agroindustriais utilizados na alimentação animal, pela técnica de ativação neutrônica. Pesquisa Agropecuária Brasileira, v.34, p.235-241, 1999.

SMITH, O.B.; OSAFO, E.L.K.; ADEGBOLA, A.A. Studies on the feeding value of agro-industrial by-products: strategies for improving the utilization of cocoa-pod-based diets by ruminants. Animal Feed Science and Technology, v.20, p.189-201, 1988.

TIGERE, T.A.; GATSI, T.C.; MUDITA, I.I.; CHIKUVIRE, T.J.; THAMANGANI, S.; MAVUNGANIDZE, Z. Potential of Jatropha curcas in improving smallholder farmers' livelihoods in Zimbabwe: an exploratory study of Makosa ward, Mutoko district. Journal of Sustainable Development in Africa, v.8, p.1-9, 2006.
VAN CLEEF, E.H.C.B. Tortas de nabo forrageiro (Raphanus sativus) e pinhão manso (Jatropha curcas): caracterização e utilização como aditivos na ensilagem de capim elefante. 2008. 77p. Dissertação (Mestrado) - Universidade Federal de Lavras, Lavras.

VARGAS-LOPEZ, J.M.; WIESENBORN, D.; TOSTENSON, K.; CIHACEK, L. Processing of crambe for oil and isolation of erucic acid. Journal of the American Oil Chemists' Society, v.76, p.801-809, 1999.

WANG, Y.P.; TANG, J.S.; CHU, C.Q.; TIAN, J. A preliminary study on the introduction and cultivation of Crambe abyssinica in China, an oil plant for industrial uses. Industrial Crops and Products, v.12, p.47-52, 2000.

WILLIAMS, S. (Ed.). Official methods of analysis of the Association of Official Analytical Chemists. $14^{\text {th }}$ ed. Arlington: AOAC International, 1984.

Recebido em 15 de maio de 2009 e aprovado em 30 de setembro de 2009 